\title{
The Application of Formative Assessment with the Involvement of Students in English Teaching
}

\author{
Xiulian $\mathrm{Liu}^{1, \mathrm{a}}$ and Yao $\mathrm{Li}^{2, \mathrm{~b}}$ \\ ${ }^{1}$ Foreign Language School of Jianghan University, Wuhan, 430056, China \\ ${ }^{2}$ Electromechanical Engineering School of Jianghan University, Wuhan, 430056, China \\ aliuxiulian1000@sina.com, bylly111@sina.com
}

\begin{abstract}
Keywords: Formative assessment with the involvement of students; Self-assessment; Peer assessment; English teaching
\end{abstract}

\begin{abstract}
Evaluation is an important part of English teaching. It can not only make a teacher find out the problems and adjust teaching methods, but also help the students diagnose the weakness in their learning process, esp. in formative assessment with the involvement of students. Through the self-assessment and peer assessment, the students can become active in detecting the problems in their study, which is helpful in constructing their knowledge system. When their classmates do a good job, they will easily build their own self-confidence, for all of them are in the same condition and if their classmates can do, they believe they can also do.
\end{abstract}

\section{Introduction}

The modern digital technology has caused the revolution not only in many aspects of our life, but also in English teaching[1]. The traditional one-way instruction style in teaching has been changed by the various interactions between teachers and students, such as in the classroom or on line. The multimedia and the network help a teacher to teach the students a great deal of knowledge vividly not only from what they see, but what they hear and even what they experience. However, no matter how much the students are taught, the focus of this process is on information input. We are not sure whether the students have a good command of what they have studied. We need a feedback, and esp. an introspection process after the input of knowledge. Through reflection and introspection, we may find out what the students have mastered and what they have not. In recent years, education evaluation has received more attention, esp. in English teaching. However, the guidance based on the evaluation to the study of students is not so remarkable although we have done a lot of jobs, which seldom require the involvement of students. So, it is necessary to review these evaluation theories we have used in teaching and invite students to involve in order to improve English teaching efficiency.

\section{The Main Evaluations Theories Applied in English Teaching}

The evaluation is an important part of English teaching, which can not only be goal-oriented, diagnostic, and incentive, but also be helpful in identification and decision-making. According to R.W.Tyler, education evaluation is to test if the learners have achieved what an education goal requires. He believes that all the evaluation methods should be designed based on the definite goal[2]. From1950s, Brown, a professor from Chicago University, assumes that the evaluation should focus on the ability of individual. He suggests three kinds of evaluations in his theory: diagnostic assessment, formative assessment and summative assessment[3]. In 1960s, Stufflebeam raised CIPP evaluation model, which emphasizes on context evaluation, input evaluation, process evaluation and product evaluation[4]. Even today, these theories are very popular in the teaching field[5]. They are used to measure the teaching efficiency to diagnose the problems in teaching. From these evaluation models, we can see it depends on how teachers deal with the information they get to evaluate[6]. Maybe, all the teachers know the problems quite well through analyzing the materials they get, but actually, students have no idea why they have such kind problems in their study, for students are not 
involved into all these evaluations. The current evaluations in English teaching are, almost, conducted by teachers and administrators. Based on the syllabus, they design the items of the evaluation which will be used to diagnose the problems in students study and to measure the ability of the students in their study. This kind of evaluation is almost involved in all the English teaching process.

\section{The Existing Problems in English Teaching Evaluation}

Evaluation has played, indeed, an important role in English teaching. The items in evaluation designed by teachers and administrators can not only test if the students have achieved what they are required, but also direct them what they should do[7]. It seems that this evaluation is very reasonable. However, the purpose of evaluation is not only to test the ability of students' study, esp. in formative assessment[8]. Only do the students find out their problems through their own self-reflection, they can understand what they need to improve. But many current evaluations in English teaching are conducted by teachers or administrators. The students are passive in the whole process of evaluation. After the evaluation, they are only told the problems they have. Lack of the process of the involvement, they are not easy to diagnose the problems in their study respectively. They cannot take more initiative in detecting the problems they have. The evaluation with the involvement of students, just like a mirror, can help them to make self-reflection. However, in English teaching, students are seldom involved into this kind of evaluation.

\section{The Application of Formative Assessment with the Involvement of Students in English Teaching}

The Importance of Evaluation with Involvement of Students. The evaluation in English teaching relates to both the teachers' job and the students' study. Its purpose is not only to help teachers or administrators to measure the ability of students, but also help students to diagnose the problems in their study. For them, the evaluation is just like a mirror, which can help them easily self reflect[9]. With this experience, it is easy to find out the problems in their study.

The Application of Formative Assessment with the Involvement of Students in English Teaching. In English teaching, the evaluation can help teachers find out the problems in their jobs, and then they can adjust their teaching methods, esp. in formative assessment[10]. In this paper, the application of evaluation model with the involvement of students will be illustrated in Business English writing and speaking.

The Application of Formative Assessment with Involvement of Students in Business English Writing Teaching.

In the Business English writing class, if the evaluation only focuses on how a teacher corrects the students' papers, the students will not take initiative to detect their problems, for they are not able to fully understand and figure out the weakness in their papers. Therefore, in practice, we invite students to participate this assessment process so that they can easily figure out their weakness from their own experience like self-assessment and peer assessment.

Teacher's Guidance in the Design of Evaluation

In order to make students understand what a good composition should involve, it is quite necessary for a teacher to design the items to evaluate their compositions. A good composition should involve, generally, five aspects such as the content, the structure, logical reasoning, cohesion and coherence, and the language expression. Teachers distribute the evaluation standards to students and then illustrate how to use these standards to evaluate a composition.

Self-assessment

With the teacher's guidance, students make self-assessment on their own compositions respectively. When they change their positions from learners to reviewers, it is easy for them to find out the weakness in their own compositions. And based on the items of evaluation and a good example of the composition (which is selected by the teacher), it will increase their self-confidence, because the good composition is written by their classmate, not a teacher or a famous writer, which 
convinces them that they themselves can also create a good one. Today, formative assessment on web-based environment becomes very popular and convenient, which can also help students to diagnose their problems in their writing[11].

Peer Assessment

Peer assessment is a process that the students play the role of a teacher and shoulder the teachers' responsibility, read other classmate's composition, revise the composition and give some advice for it. This is based on the cooperative learning theory.

First of all, the teacher divides students into several groups (usually five or six for a group), making sure that members in each group are balanced and can achieve the purpose of mutual help in the group discussion. Teachers provide students with many different levels of business writings, and then guide the students to evaluate them from the aspects such as the content, the structure, logical reasoning, cohesion and coherence and language expression. Teachers need to stress the responsibility in judging the composition. Every student must try to point out the advantages and disadvantages in other's composition. Based on their discussion, they are required to provide their reasonable modifications on the weakness of the composition. After the students give mutual feedback of the revisions, the teacher will make the summary and ask the students to revise and improve their own composition according to the peer feedback. The teacher will give the final evaluation according to the peer feedback and the students' revision in their composition.

This cooperative learning indicates that students need to be in a certain social group to learn and internalize what they have studied. Peer feedback provides an environment for students to discuss together and judge what they create, which stimulates students' subjective consciousness and creative consciousness.

The Application of Formative Assessment with the Involvement of the Students in Business English Speaking Teaching.

The Importance of Evaluation with Involvement of Students in Business English Speaking

Business English belongs to a kind of English for special purpose. Practicality is the most important characteristic. To judge whether a student has a good command of this course will focus on the evaluation that expects to know if they can communicate in a business context successfully in English. So, it is quite necessary to cultivate their communicative ability in business activities. Role play is an appropriate activity to allow students to learn the related knowledge in a simulated context. But evaluation on their performance in this context will help the students to diagnose the problems they have in their communication.

Definite Teaching Objectives

In the speaking class of Business English, the teaching objective of each topic can make students understand what the acceptable communication ability in a business context is. The specific requirements in the assessment are embodied in the following table, which will be used in the self-assessment, peer assessment and teacher's comments. 


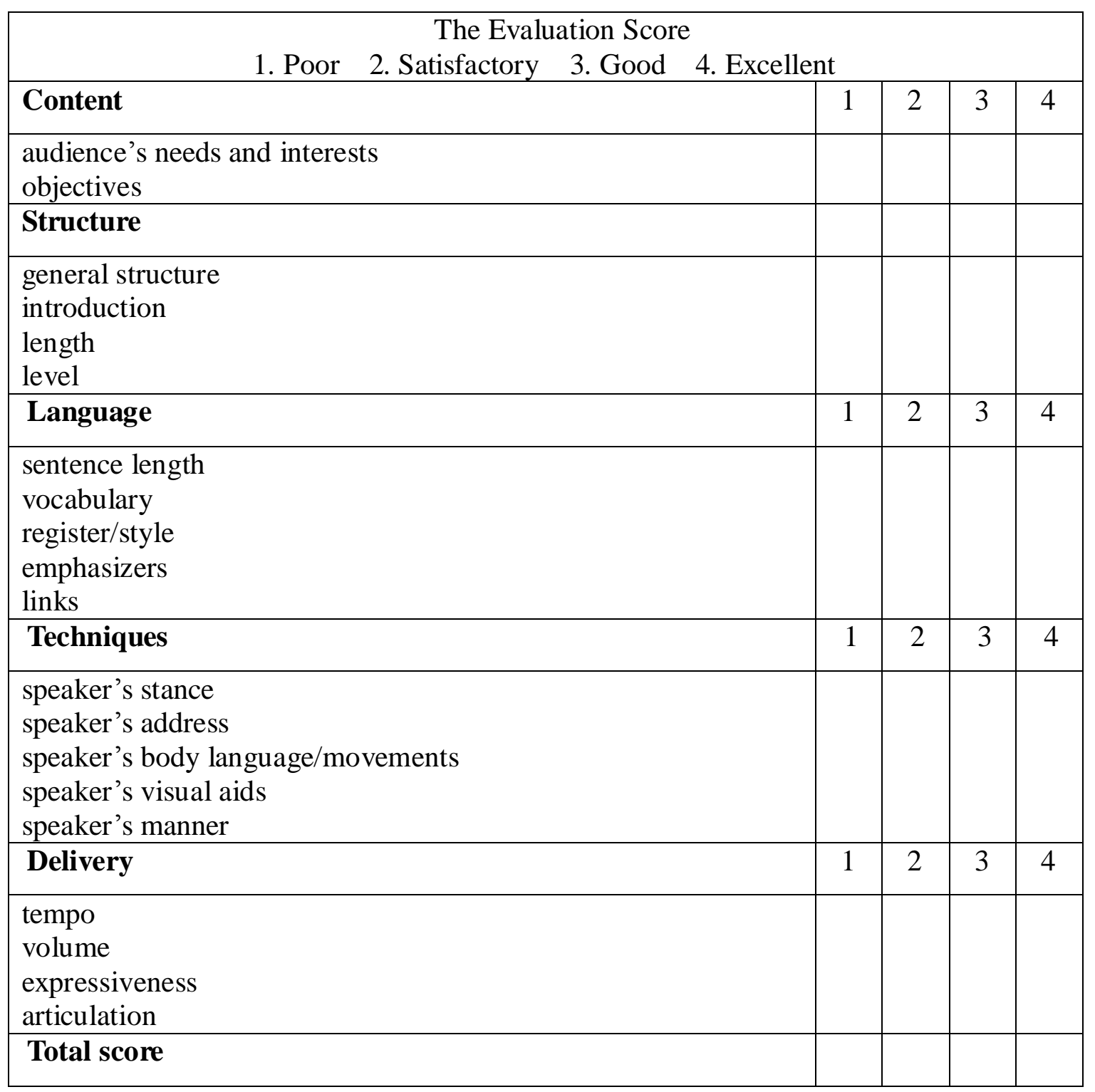

\section{Self-assessment}

In classroom teaching, role play involves different business activities in different occasions such as presentation, dialogue, meeting and negotiation. Before the self-assessment, the students must have a clear idea on the task and the requirements. Each group will perform the task before the class. Based on the evaluation items in the above table, each member in a group will assess their own performance and give scores to each item.

Peer Assessment

When students make self-assessment on their own group performance, sometimes, it is not so objective. So, the peer assessment is necessary. When a group shows a business activity before the class, the other groups evaluate on this group. They are required to not only score, but also point out the advantages and disadvantages in the activity of this group. When they evaluate, actually, they can reflect about themselves. Maybe, they also have these problems. If a group does a good job, the other groups can benefit. Through this peer assessment, it is easy for students to find out their own problems in the study, and they can learn from each other.

Teacher's Comments

The self-assessment and peer assessment can help students to reflect what they have studied. However, sometimes, maybe it is not so overall. It is necessary for a teacher to give the total comments on what students have done. The comments should be specific and targeted. The teacher not only needs to give the feedback positively, but more important thing for him/her to do is to point out the deficiencies. With the comparison between teacher's comments and students' 
assessment, the students can identify problems they have. This will guide students to improve in their learning process.

\section{Conclusion}

The evaluation with the involvement of students regards the students as a necessary part in English teaching, esp. in formative assessment. It emphasizes the role of students in evaluation. The internalizing of knowledge must be realized through the students' self-reflection. Also, with the involvement of students in evaluation, teachers can detect the problems in teaching. The adjust of their teaching methods will become more targeted. The self-assessment and the peer assessment provide students with the chance to diagnose the problems in their study more accurately. When the problems they have are pointed out by their classmates, their experience will become more impressive. This self-reflection can not only help them find out the problems, but also motivate them to improve positively. They become more active and more creative.

\section{References}

[1] Bao Xiaoli. "The Reform of the Mode of Business English under Multimedia Network", Ethnic Higher Education Research [J], 2014.

[2] The Yearbook Committee and Associated Contributors. Edited by Ralph W.Tyler. Education Evaluation: New Roles, New Means [M].Chicago: the University of Chicago Press , 1969.

[3] Lorin W.Anderson \& David Krathwohl.A Taxonomy for Learning, Teaching, and Assessing: A Revision of Bloom's Taxonomy of Educational Objectives .New York: Longman,c 2001.

[4] Stufflebeam, D.L.. The CIPP Model for Evaluation. In D.L.Stufflebeam, \& T.Kellaghan,(Eds.), The International Handbook of Educational Evaluation (Chapter 2). Boston:Kluwer Academic Publishers.2003.

[5] Stufflebeam, D.L.. Evaluation as Enlightenment for Decision-Making. In H.B.Walcott (Ed.), Improving Educational Assessment and an Inventory of Measures of Affective Behavior (PP.41-73). Washington, DC: Association for Supervision and Curriculum Development and National Education Association.1969.

[6] Wu Fei. The Application of CIPP mode in Curriculum Evaluation in Universities. China Higher Education Evaluation [J]. 2(2007).

[7] Wang Xiaoling. Education evaluation theory and technology [M]. Shanghai: Shanghai Education Press, 1999.

[8] Liu Yuli, Ye Haili \&Ge Liezhong. The Empirical Study on Teacher Teaching Evaluation in Universities. Education for Chinese After-School [J]. 9(2013)

[9] Yang Xinyao. "The Practice and Reflection of Formative Assessment in College English Teaching". Journal of Liaoning Institute of Education Administration [J]2011

[10] Su Weihuang. The Study of Formative Assessment in Foreign Language Teaching. Journal of Social Science of Human Medical University. 7(2009).

[11]Liu Hong. The Study of Formative Assessment mode on Web-based Teaching Environment. Journal of Mudanjiang College of Education. [J]. 4(2011). 